\title{
Prevalence of tobacco use among adults in Ramanathapuram village of Pondicherry
}

\section{Iswarya Santhanakrishnan, Sitanshu Sekhar Kar, Ganesh Kumar S}

Department of Preventive and Social Medicine, Jawaharlal Institute of Post Graduate Medical Education and Research, Puducherry, India

Address for the Correspondence:

Dr. Iswarya Santhanakrishnan,

Department of Preventive and Social Medicine, Jawaharlal Institute of Post Graduate Medical Education and Research

Pondicherry - 605 006, India. E-mail: Ishwarya3386@gmail.com

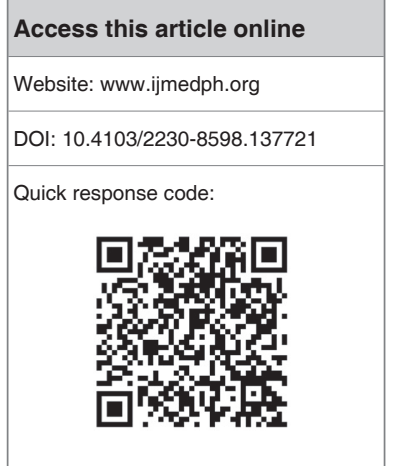

Background: Tobacco use in any form has increased throughout the world. Total tobacco related deaths are projected to rise from 5.4 million in 2004 to 8.3 million in 2030 globally. In India, eight to 10 lakh people die due to tobacco related disease every year. The Global adult tobacco survey (GATS) in India in 2009-2010 revealed that 163.7 million use the smokeless form, 68.9 million smoke, 42.3 million use both smoking and smokeless form of tobacco. Aim and Objective: To find the prevalence, reasons for initiation, willingness to quit tobacco among adults ( $\geq 20$ years) in Ramanathpuram village of Jawaharlal Institute of Postgraduate Medical Education and Research (JIPMER) rural health centre service area. Materials and Methods: A cross sectional survey was carried out among adults $>20$ years $(n=315)$ in one of the four villages of rural field practice area of the JIPMER, Pondicherry. Considering prevalence of tobacco use as $25 \%$, with $20 \%$ relative precision, sample size was calculated to be 300. Interns trained in interview techniques collected information using a structured questionnaire after taking informed consent. Data were collected on demographic parameters, current tobacco use, age at initiation, reasons for initiation, harmful effects of tobacco, sources of information and the willingness to quit. Result: Among the 315 people studied, 51.42\% were males. Seventy-nine of them (20.6-30.1) used tobacco in any form. The proportion of females exceeded males in the use of smokeless tobacco. The age of initiation of smoking was found to be $22.6 \pm 5.7$ years, earlier than that for the smokeless form $27.5 \pm 12.2$ years $(P=0.032)$. The majority $(50.6 \%)$ initiated tobacco use due to peer pressure, followed by influence of their family members (30.3\%) and stress (17.7\%). Although awareness about the harmful effects of tobacco was found in $64 \%$ (58.3-68.9) of the subjects, only $21.9 \%(13.06-32.2)$ of the tobacco users were willing to quit. Conclusion: About one-fourth of the study population used tobacco but only about one fifth of the users were willing to quit. Hence, targeted awareness activities will be needed for those unwilling to quit tobacco use.

Key Words: Awareness, prevalence, tobacco

\section{INTRODUCTION}

Tobacco use continues to be the leading cause of preventable death worldwide. However, the burden of tobacco use is shifting from the developed to developing countries. Tobacco use in low-income and middle-income countries is predicted to contribute to an increasing share of the global burden of disease in future decades. Total tobacco related deaths are projected to rise from 5.4 million in 2004 to 8.3 million in 2030 globally. ${ }^{[1]}$ In India, eight to 10 lakh people die due to tobacco related disease every year. ${ }^{[2]}$ The global adult tobacco survey (GATS), India revealed that more than one-third $(35 \%)$ of adults in India use tobacco in some form or the other. GATS figures in 2009-2010 for India revealed that 163.7 million people use the smokeless form, 68.9 million smoke while 42.3 million use both smoking and smokeless form of tobacco. ${ }^{[3]}$ Tobacco-related cancers constitute about half of the total cancer incidence among men and about $20 \%$ among women. ${ }^{[4]}$ Tobacco use often begins before adulthood. ${ }^{[5]}$ In India, recent data suggest an increase in the prevalence of regular tobacco use among urban teens in Delhi and Mumbai since 2001. ${ }^{[6]}$ The tobacco situation in India is unique because of a vast spectrum of tobacco products available for smoking as well as smokeless use. The risks of tobacco use are highest among those who start early and continue its use for a long period. Reasons for initiation into smoking differ across cultures. Identification of factors associated both with smoking initiation and cessation may help to underpin strategies to aid cessation. There is a need 
for locally relevant community based data regarding the pattern of tobacco use, knowledge regarding quitting behavior for designing effective community based intervention strategies. Given that an intention to quit smoking is shown to be one of the key steps in the process towards smoking cessation, it is important to study all quit attempts, even those that are unsuccessful in order to adequately address all barriers to smoking cessation among smokers and increase the proportion of successful quit attempts. This study was carried out to find the prevalence of tobacco use, reasons for initiation and willingness to quit among adults over 20 years.

\section{MATERIALS AND METHODS}

A descriptive study was carried out among the population under the Rural Health Centre (RHC), Ramanathapuram, which is a rural field practice area of Department of Preventive and Social Medicine, Jawaharlal Institute of Postgraduate Medical Education and Research (JIPMER). The RHC provides holistic care to 2,132 households covering a population of 9,101 in four villages namely Ramanathapuram, Pillayarkuppam, Thuthipet and Thondamanatham by providing comprehensive preventive, promotive, curative and rehabilitative services. Considering prevalence of tobacco use as $25 \%$, with $20 \%$ relative precision, the sample size was calculated to be 300 . Adults over 20 years were selected by convenience sampling from one of the service areas. Study subjects were contacted, informed consent was obtained and they were interviewed. Data collection was carried out by trained interns using a pre-tested structured questionnaire and supervised by investigators. Data on socio-demographic factors, tobacco use, age at initiation, harmful effects of tobacco, source of information and willingness to quit tobacco was collected.

Interns were trained in the administration of the questionnaire, the data collection process and were supervised by the investigators.

The operational definition for current and past smokers was as follows:

Current daily user: Uses tobacco products every day, over a period of one month or more; Occasional user: Uses tobacco products less than daily in the past one month;

Past user: Not used tobacco in the past one month.

Data was entered and analyzed by using the IBM-SPSS for Windows (Statistical Package for Social Sciences) version 20. The findings were expressed in terms of proportions. The Chi-square test was used to study the association between socio-demographic factors and tobacco use. A $P$ value less than 0.05 was considered statistically significant.

\section{RESULTS}

A total of 315 subjects were included in the study. Baseline characters of the participants are depicted in Table 1 . There was almost an equal distribution of males and females at $51.42 \%$ and $48.58 \%$ respectively.
The majority of study subjects $71.2 \%$ (224) were literate. Around $44.8 \%$ (141) were skill I workers followed by $43.2 \%$ (136) skill II workers. Most of the subjects $67.9 \%$ (214) belonged to nuclear families but $32.1 \%$ (101) were from joint families [Table 1].

Out of 315 subjects, $25.1 \%$ (79) were using tobacco in any form. Among the 79 tobacco users, 42 were smokers, 44 used smokeless tobacco and 7 used both the forms. Among the smokers, the majority $73.8 \%$ (31) were current daily users, $14.2 \%$ (6) current occasional smokers and $11.9 \%$ (5) were past smokers. Among smokeless tobacco users, $68.1 \%$ (30) were current daily users, $22.7 \%$ (10) current occasional users and $9 \%$ were past users. The proportion of females exceeded males in the use of smokeless tobacco. The age of initiation of smoking was $22.6 \pm 5.7$ years, earlier than for the smokeless form $27.5 \pm 12.2$ years $(P=0.032)$. The prevalence of tobacco use in our study population was $25.1 \%$, prevalence of smoking $13.3 \%$ and prevalence of smokeless tobacco use was $13.9 \%$ [Table 2].

\begin{tabular}{lc}
$\begin{array}{l}\text { Table 1: Socio-demographic details of the study } \\
\text { population }\end{array}$ \\
\hline Characteristic & Participants (\%) \\
\hline Age in years & \\
$20-29$ & $72(22.9)$ \\
$30-39$ & $56(17.8)$ \\
$40-49$ & $64(20.3)$ \\
$50-59$ & $46(14.6)$ \\
$\geq 60$ & $77(24.4)$ \\
Gender & \\
Male & $162(51.42)$ \\
Female & $153(48.58)$ \\
Education Status & \\
Literate & $91(28.8)$ \\
Illiterate & $224(71.2)$ \\
Occupation & \\
Skill I & $141(44.8)$ \\
Skill II & $136(43.2)$ \\
Skill III & $34(10.8)$ \\
Skill IV & $4(1.3)$ \\
\hline
\end{tabular}

\begin{tabular}{lc} 
Table 2: Distribution of tobacco users in the study \\
population & Participants (\%) \\
\hline Tobacco use status & $79(25.1)$ \\
\hline Users & $236(74.9)$ \\
Non users & \\
Type of tobacco use & $42(13.3)$ \\
Smokers & $44(13.9)$ \\
Smokeless tobacco users & \\
Smoking status & $31(9.8)$ \\
Current daily user & $6(1.9)$ \\
Current occasional user & $5(1.5)$ \\
Past user & \\
Smokeless tobacco users & $30(9.5)$ \\
Current daily user & $10(3.1)$ \\
Current occasional user & $4(1.2)$ \\
Past user &
\end{tabular}


A majority $50.6 \%$ of the study group initiated tobacco use due to peer pressure, followed by $30.3 \%$ due to influence of family members, another $17.7 \%$ due to stress and $1.4 \%$ claimed to be influenced by movies [Table 3]. Among the study subjects, 64.1\% (202) were aware about at least one harmful effect of tobacco use whereas $35.1 \%$ (113) were not aware about even a single harmful effect of tobacco. Of the 79 tobacco users, only $21.5 \%$ (17) were willing to quit tobacco and majority $78.5 \%$ (62) were actually not willing to quit tobacco use [Table 4].

\section{DISCUSSION}

This study was undertaken in one of the service areas of the Rural Health Center of JIPMER among 315 subjects to find the prevalence of tobacco use. The prevalence of smoking and smokeless tobacco was $13.3 \%$ and $13.9 \%$ respectively. In the present study, the age of initiation of smoking was earlier than that of chewing tobacco. This study found the age of initiation of tobacco use to be around 22 years in contrast to many studies where the age of initiation was reported to be around 15 years. ${ }^{[3,5]}$ This discrepancy could be due to self reported age of onset of tobacco use; people may tend to report a later age for tobacco initiation. In the present study, the use of smokeless tobacco was significantly higher in females compared to males; this could be due to the misconception that smokeless tobacco products are less harmful

\begin{tabular}{lc} 
Table 3: Reasons for initiation & \\
\hline Reasons & Number (\%) \\
\hline Peer pressure & $40(50.6)$ \\
Tobacco use among family members & $24(30.3)$ \\
Stress & $14(17.7)$ \\
Others & $5(1.4)$ \\
Total & $79(100)$ \\
\hline
\end{tabular}

\begin{tabular}{lc} 
Table 4: Willingness to quit tobacco \\
\hline Willingness to quit & Number of responses (\%) \\
\hline Yes & $17(21.5)$ \\
No & $62(78.5)$ \\
Total & $79(100)$ \\
\hline
\end{tabular}

than smoking. The most common reason cited for initiation of tobacco use was peer pressure which is similar to other studies. ${ }^{[7]}$ In the study population, $64 \%$ of them were aware about at least one harmful effect of tobacco but only $21.1 \%$ of them had been willing to quit tobacco in the past 6 months.

\section{CONCLUSION}

About one fourth of the study population under the RHC of JIPMER used tobacco. However, the worry was that only one fifth of them were willing to quit tobacco use. It is therefore suggested that targeted awareness activities be planned for those unwilling to quit tobacco as well as for those unaware of its harmful effects.

\section{REFERENCES}

1. Mathur P, Shah B. Research priorities for prevention and control of noncommunicable diseases in India. Indian $\mathrm{J}$ Community Med 2011;36:S72-7.

2. WHO | WHO report on the global tobacco epidemic, 2011. Warning about the dangers of tobacco [Internet]. WHO. Available from: http://www.who. int/tobacco/global_report/2011/en/ [Last cited on 2013 Oct 18].

3. Global Adult Tobacco Survey (GATS) India [Internet]. New Delhi: Minsitry of Health and Family Welfare. Available from: http://www.downtoearth. org.in/category/thesaurus/global-adult-tobacco-survey-gats-indiareport-2009-10 [Last updated on 2013 Oct].

4. Sorensen G, Gupta PC, Pednekar MS. Social disparities in tobacco use in Mumbai, India: The roles of occupation, education, and gender. Am J Public Health 2005;95:1003-8.

5. Narain R, Sardana S, Gupta S, Sehgal A. Age at initiation and prevalence of tobacco use among school children in Noida, India: A cross-sectional questionnaire based survey. Indian J Med Res 2011;133:300-7.

6. Reddy KS, Perry CL, Stigler MH, Arora M. Differences in tobacco use among young people in urban India by sex, socioeconomic status, age, and school grade: Assessment of baseline survey data. Lancet 2006;367:589-94.

7. Gunaseelan R, Sankaralingam S, Ramesh S, Datta M. Areca nut use among rural residents of Sriperambudur Taluk: A qualitative study. Indian J Dent Res 2007;18:11-4.

How to cite this article: Santhanakrishnan I, Kar SS, Kumar SG. Prevalence of tobacco use among adults in Ramanathapuram village of Pondicherry. Int J Med Public Health 2014;4:298-300.

Source of Support: Nil, Conflict of Interest: None declared. 